\title{
Exposure to smoking in films and smoking behaviour among Norwegian 15- to 20-year-olds: a cross-sectional study
}

\author{
Gunnar Sæbø * \\ Norwegian Institute for Alcohol and Drug Research (SIRUS) \\ Email: gs@sirus.no \\ ${ }^{*}$ corresponding author

\section{Ingeborg Lund} \\ Norwegian Institute for Alcohol and Drug Research (SIRUS) \\ Email: il@sirus.no
}

\begin{abstract}
Studies from several countries have revealed significant effects of exposure to smoking in films on smoking behaviour and attitudes among adolescents. This study presents the first findings from the Scandinavian cultural region on this topic. With the objective to test for significant adjusted relationships between exposure to smoking in films and established smoking among 15- to 20-year-old respondents, and susceptibility to smoking among non-smokers in the same age group, a cross-sectional study was conducted in June 2008. 807 Norwegian adolescents and young adults answered a web-based questionnaire. Exposure to smoking in films is estimated by asking the respondents if they had seen films from a list of 56 popular film titles of both local and foreign origin from 2007 and 2008. Associations of exposure and smoking behaviour are tested in two logistic regression models. Respondents with the highest exposure to film smoking are more likely to be established smokers than those with no exposure (adjusted odds ratios=2.22, confidence interval=1.04-4.77). Among non-smokers, those with highest exposure to smoking in films are more likely to be susceptible to smoking than those with no exposure (adjusted odds rations $=1.55$, confidence interval=0.93-2.56). Film smoking is significantly associated with smoking susceptibility and established smoking among Norwegian adolescents and young adults.
\end{abstract}

Keywords: exposure to smoking in films, smoking initiation, media effects, movies, adolescents and young adults, motion pictures - content ratings 


\section{Introduction}

\section{Background}

Even though cigarette smoking is decreasing in Europe, tobacco remains a considerable risk to public health. To prevent future tobacco-related mortality, it is important to keep encouraging youths to refrain from experimenting with addictive tobacco products. Although most European countries now prohibit tobacco advertising, it is still possible to find depictions of tobacco smoking in audio-visual media, that is, movies, television, and the Internet. Of the various media, however, the medium of movies is unique in its capacity to evoke different sensations in the audience. In recent times, western states have been reluctant to censor artistic expression, and the smoking of tobacco on film has yet to be regulated as tobacco advertising or indeed actual smoking practice is today. Movies, in other words, constitute a means of expression in which filmmakers are still at liberty to portray the use of tobacco more or less as they wish. What does this entail with respect to the medium's potential to depict and promote tobacco use?

\section{The film-smoking-exposure effect}

Observational studies have shown that exposure to film smoking exerts an independent statistical dose-response effect on smoking susceptibility, experimentation, and initiation among children and adolescents, after controlling for relevant confounders (Sargent et al., 2001, 2002, 2005, 2007; Dalton et al., 2003, 2009; Song et al., 2007; Titus-Ernstoff et al., 2008). The more episodes of smoking that youngsters experience, the more likely they are to experiment with tobacco and to become smokers. Experimental research has reached similar conclusions (Pechmann \& Shih, 1999; Hines et al., 2000). In the following, this effect will be designated as the 'film-smokingexposure effect'. The suggested underlying mechanism in this process of influence is mediating attitudes (Sargent, 2006). Supposedly smoking in films communicates positive values of tobacco, and exposure to film smoking will therefore contribute to the development of positive attitudes to smokers and smoking among adolescents. Increased smoking susceptibility might follow, which eventually may lead to smoking experimentation (Sargent et al., 2002). On the grounds of this research, public-health advocates have taken the initiative to include depiction of smoking as a criterion in film ratings, giving all films with smoking scenes an 18-year age limit. The World Health Organization (WHO) has embraced this initiative and has consequently recommended this action as part of the implementation of the WHO Framework Convention on Tobacco Control (WHO, 2011). Parents also tend to support such ratings (McMillen et al., 2007).

\section{Differences in the effect of exposure to smoking in movies among national and social groups}

Despite several empirical studies detecting significant effects of exposure to smoking in films, the findings in this field are still subject to some uncertainty. First, there are empirical nuances in relation to national-cultural contexts, which suggest caution in generalizing the effect to any population without reservation. The second uncertainty, related to the first, there are variations among social and ethnic subgroups regarding the magnitude and interaction 
patterns of the association. The studies referred to in the previous section are all from the United States, with several of them based on the same regional data set from small states in the New England region (Vermont and New Hampshire). Also, the movies were all produced in Hollywood and the US.

Regarding findings from other countries, effects similar to those in the US were found in Mexico, albeit somewhat weaker (Thrasher et al., 2008, 2009). In Egypt significant effects were found only for boys (Islam \& Johnson, 2007), in Germany (Hanewinkel \& Sargent, 2007) and the United Kingdom (Waylen et al., 2011) similar effects as in the US were revealed, while studies from Scotland (Hunt et al., 2009, 2011) have produced conflicting results. A recent cross-cultural study in six European countries has found significant associations in the Netherlands, Poland, Italy, and Iceland, providing a strong case for the generalizability of these results to central Europe (Morgenstern et al., 2011, 2013).

In relation to ethnicity and cross-cultural dynamics, the existing knowledge is ambiguous: regarding differences between black and white adolescents, one US study found significant effects of film exposure among 'white youth' but not among 'blacks' (Jackson et al., 2007), while another study that distinguished between exposure to 'black-oriented' movies and 'mainstream' movies found an effect among blacks of exposure to black-oriented films, but not of exposure to mainstream films (Dal Sin et al., 2013). A Texan study found a stronger (and more monotonic) effect among Mexican-born Texans than among US-born youngsters (Wilkinson et al., 2009).

No studies of the role of film smoking in smoking initiation have yet been undertaken in Norway, or indeed in the Scandinavia. Norway is a small country with a small domestic film output, and movies from the US and the UK dominate the market. These movies are often said to purvey 'Coca-Cola-ized' values and ideas that many young people find attractive.

\section{Film-smoking exposure in late adolescence}

The age group observed in the bulk of the previous research in this field comprises 10-14-year-olds. Smoking initiation also occurs among older adolescents and young adults. In Norway for instance, the mean age for smoking initiation is 17.8 for boys and 18.3 for girls (Skretting et al., 2015:138). Consequently, the influence of the media may still be in operation among individuals in their late teens. However, only a handful of studies have investigated exposure to smoking in films among older adolescents or young adults, or both. While a cross-sectional study has found a significant adjusted dose-response relationship among 18-25-year-olds, and one longitudinal study has found early exposure to movie smoking to predict later established smoking (Dalton et al., 2009), a second longitudinal study has found no significant association between late exposure to movie smoking and established smoking (Primack et al., 2012). All these studies were conducted in the US.

Because previous studies have found that adolescents who are otherwise at low risk for smoking initiation have been particularly susceptible to the influence of smoking in films (Dalton et al., 2003; Hanewinkel \& Sargent, 2008), an additional topic of interest is whether such interaction effects are 
found also among older teens and young adults. No one has investigated this aspect so far. If such interaction effects are at work even among older adolescents, it would provide an even stronger reason to impose age ratings to regulate access and impulses to smoke via movies (Millett \& Glantz, 2010). As European youth largely seem to have access to more smoking scenes than American youth (Hanewinkel et al., 2013), it is important to investigate whether smoking scenes occur in movies that are rated as suitable for children and young adolescents, or in movies rated as suitable for adults.

\section{Research problem}

This study explores exposure to smoking in films and its association with smoking behaviour in Norway. To what extent do smoking incidents occur in popular films, and are there differences between movies in the number of smoking scenes according to age ratings? Smoking behaviour is defined as established smoking among all adolescents and young adults (aged 15-20 years) and as susceptibility to smoking among non-smoking adolescents and young adults in the same age group. Are any relationships maintained after controlling for other relevant influences, and what are the indications of interaction effects, if any?

\section{Materials and methods}

\section{Sample}

Respondents were recruited from a web panel of approximately 60000 individuals of all ages, run by the public opinion institute IPSOS MMI. The members of this panel were originally contacted randomly by telephone to participate in unique studies, but then asked if they were willing to become a member of the web base, to be contacted later for other research projects via the Internet. This base is thus a random sample of individuals who are willing to participate in online surveys. In Norway, Internet access is now almost universal (95 per cent), primarily lacking among those over 65 years of age (www.ssb.no/ikthus).

From this pool, all available respondents between $15-20$ years $(\mathrm{N}=2227)$ were contacted for participation in an online survey between June and August 2008. In all, 807 participants agreed to participate, making the response rate 36 per cent. To strengthen representativeness, the sample was weighted by gender, age, and region. The prevalence of current smokers in this online sample was 22 per cent, which is almost identical to the official number of smokers in the same age group (21 per cent), as provided by Statistics Norway (Vedøy \& Skretting, 2009).

\section{Exposure to film smoking}

To arrive at a measure for exposure to smoking in films, respondents were first presented with a list of 56 films, and asked 'Which of the following films have you seen?' These 56 titles emerged after adding together and subsequently removing duplicates from three lists of popular films: the top 30 box-office 
successes in Norwegian cinemas in 2007, the 25 most frequently bought films on DVD in 2007, and the top 20 box-office successes in Norwegian cinemas during the first four months of 2008 (www.kino.no). To help respondents in their recall, they were mounted with a copy of the advertising poster/DVD cover for the film in addition to the film title.

All titles were content analysed and smoking scenes were coded by trained coders (the first author and two research assistants). On the basis of a previously validated method (Dalton et al., 2002), a smoking scene was demarcated as distinctive in narrative time and space, and defined as any depiction of smoking or smoke, associated with the use of combustible tobacco, by a central or peripheral character, or in the background (for instance in a bar). In addition, we included visual still depictions of smoking packs, ashtrays, advertising boards, and so on, because such representations are known to function as smoking cues (Lochbuehler et al., 2010, 2011). Verbal exchanges about smoking were not coded, and in line with customary practice in the literature, we did not attempt to distinguish between exposure to 'positive' and 'negative' depictions or 'good guys' or 'bad guys' smoking.

There were 246 smoking scenes in these 56 films. On the basis of which films the respondents had seen, a sum-score index was computed to measure each individual's total exposure to smoking scenes (i.e., summarizing the total number of smoking scenes each respondent had seen in the films he or she had ticked for). To enable comparison of the results of this study with previous studies, we recoded the exposure to scenes of smoking in films into quartiles.

\section{Susceptibility}

Smoking susceptibility can be defined as willingness to experiment with tobacco, and was measured using two standard questions to non-smokers (Pierce et al., 1996): 'Do you think you will smoke at least one cigarette in the next six months?' and 'If one of your best friends offered you a cigarette at a party, would you smoke it?' Answer categories ranged from 'definitely not' to 'definitely yes', with the additional option 'seldom with friends at parties' for the second question. Those who answered 'probably not', 'probably yes' or 'definitely yes' to any of these two questions were defined as 'susceptible'.

\section{Established smoking}

Established smoking was measured using the standard formulation of life-time smoking experience: 'How many cigarettes have you smoked in your life?' Several response alternatives ranged from 'none' to '100 cigarettes or more'. Those who had smoked 100 cigarettes or more were defined as 'established smokers'.

\section{Other risk factors}

Social influence was measured using several questions on smoking and drinking habits in the family and among friends, as listed and described in Table 1. All social influence variables were recoded into dummy variables with cut-offs at 'yes' for maternal, paternal, and sibling smoking, 'once a week' for parental drinking frequency, and 'about half' for proportion of peers smoking daily or occasionally and peers getting drunk once a week. Parental style was 
measured using the Authoritative Parenting index (Cronbach's Alpha=0.71) (Jackson et al., 1998).

Individual traits were measured using established indices for sensationseeking (five items, Cronbach's Alpha $=0.56$ ), rebelliousness (6 items, Cronbach's Alpha $=0.66$ ) and self-esteem (seven items, Cronbach's Alpha $=0.79$ ). Items measuring sensation-seeking and rebelliousness were combined into a sensation-seeking/rebelliousness index, which provided acceptable reliability (Cronbach's Alpha $=0.75$ ). All items measuring risk factors metrically were recoded before the construction of indices, so that higher scores would signify more of the actual characteristic. The socio-demographic background variables were gender (male/female) and age (15-16/17-18/1920).

\section{Statistical analysis}

This study applied binary logistic regression analysis to estimate unadjusted and adjusted associations between exposure to smoking in films and established smoking (among all adolescents) and between exposure to smoking in films and susceptibility to smoking (among non-smokers).

To test if new variables contributed significantly to the model, controls were entered sequentially (block-wise), in the following order: socio-demographics, individual traits, and social influence. Significant contribution of each block was tested by changes in the log-likelihood levels.

To look for interaction effects, three-way analyses of associations between film exposure and prevalence of established smoking/susceptibility in sub-groups were performed.

\section{Results}

\section{Description of the sample}

Table 1 shows the distributions of responses to smoking behaviour and sociodemographics (as well as the risk factors that were measured categorically). Of the respondents 12.9 per cent were established smokers, having smoked more than 100 cigarettes in their lifetime. Among non-smokers, 37.5 per cent were susceptible to smoking.

\section{Exposure to smoking in the films}

The 246 smoking scenes in the 56 films studied were unevenly distributed among the films. Only nine per cent of the films had 20 or more smoking scenes, while 14 per cent had five to 19 scenes (figure 1). The vast majority of smoking scenes (90 per cent) occurred in films rated with the minimum age requirements of 11 and 15 years. 
Table 1. Descriptive statistics of the sample, percentages.

\begin{tabular}{|c|c|c|c|}
\hline Variables & & $\begin{array}{l}\text { Total } \\
\text { sample } \\
(\mathrm{n}=807)\end{array}$ & $\begin{array}{l}\text { Non- } \\
\text { smokers } \\
(n=631)\end{array}$ \\
\hline \multicolumn{4}{|l|}{ Demography } \\
\hline $\begin{array}{l}\text { Gender } \\
\text { Age }\end{array}$ & $\begin{array}{l}- \text { men } \\
- \text { women } \\
-15 / 16 \\
-17 / 18 \\
-19 / 20\end{array}$ & $\begin{array}{l}51.9 \\
48.1 \\
37.6 \\
33.4 \\
29.0\end{array}$ & $\begin{array}{l}53.0 \\
47.0 \\
42.4 \\
31.3 \\
26.4\end{array}$ \\
\hline \multicolumn{4}{|l|}{ Social influence } \\
\hline $\begin{array}{l}\text { Does your } \\
\text { father/stepfather smoke? }\end{array}$ & $\begin{array}{l}\text {-no/don't know/don't have a father or } \\
\text { stepfather } \\
\text {-yes }\end{array}$ & $\begin{array}{l}78.5 \\
21.5\end{array}$ & $\begin{array}{l}81.5 \\
18.5\end{array}$ \\
\hline $\begin{array}{l}\text { Does your } \\
\text { mother/stepmother } \\
\text { smoke? }\end{array}$ & $\begin{array}{l}\text {-no/don't know/ don't have a mother } \\
\text { or stepmother } \\
\text {-yes }\end{array}$ & $\begin{array}{l}76.9 \\
23.1\end{array}$ & $\begin{array}{l}78.2 \\
21.7\end{array}$ \\
\hline Do your siblings smoke? & $\begin{array}{l}\text {-no/don't know/ don't have siblings } \\
\text {-yes }\end{array}$ & $\begin{array}{l}80.1 \\
19.9\end{array}$ & $\begin{array}{l}82.2 \\
17.8\end{array}$ \\
\hline $\begin{array}{l}\text { How often do your } \\
\text { parents/stepmother or } \\
\text { stepfather drink? }\end{array}$ & $\begin{array}{l}\text {-never/once a year/once a month } \\
\text {-once a week/daily }\end{array}$ & $\begin{array}{l}50.9 \\
49.1\end{array}$ & $\begin{array}{l}52.6 \\
47.4\end{array}$ \\
\hline $\begin{array}{l}\text { Think about the youth you } \\
\text { usually spend your leisure } \\
\text { time with: approximately } \\
\text { how many of them do you } \\
\text { believe smoke daily or } \\
\text { occasionally? }\end{array}$ & $\begin{array}{l}\text {-none or almost none/less than half } \\
\text {-about half/more than half/all or } \\
\text { almost all }\end{array}$ & $\begin{array}{l}78.5 \\
21.5\end{array}$ & $\begin{array}{l}87.2 \\
12.8\end{array}$ \\
\hline $\begin{array}{l}\text { Think about the youth you } \\
\text { usually spend your leisure } \\
\text { time with: approximately } \\
\text { how many of them do you } \\
\text { believe get drunk about } \\
\text { once a week? }\end{array}$ & $\begin{array}{l}\text {-none or almost none/less than half/ } \\
\text {-about half/more than half/all or } \\
\text { almost all }\end{array}$ & $\begin{array}{l}53.6 \\
46.4\end{array}$ & $\begin{array}{l}60.4 \\
39.6\end{array}$ \\
\hline \multicolumn{4}{|l|}{ Smoking } \\
\hline Established smoking & $\begin{array}{l}\text {-no } \\
\text {-yes }\end{array}$ & $\begin{array}{l}87.1 \\
12.9\end{array}$ & - \\
\hline Susceptible to smoking & $\begin{array}{l}\text {-no } \\
\text {-yes }\end{array}$ & - & $\begin{array}{l}62.5 \\
37.5\end{array}$ \\
\hline
\end{tabular}

On average, the respondents had seen $13.1(\mathrm{SD}=10.5$ - median=14) of the 56 films presented to them. Twenty-seven per cent of the adolescents had not been exposed to any smoking scenes at all, making up the first quartile. Q1 was thus a truly unexposed group. Q2 had seen 1-39 scenes, Q3 40-89 scenes, while Q4 had been exposed to 90-246 scenes. 
Figure 1: Distribution of smoking scenes. Number of smoking scenes ( $\mathrm{N}=56$ films) and rating of smoking scenes ( $\mathrm{N}=246$ scenes), in percentages.

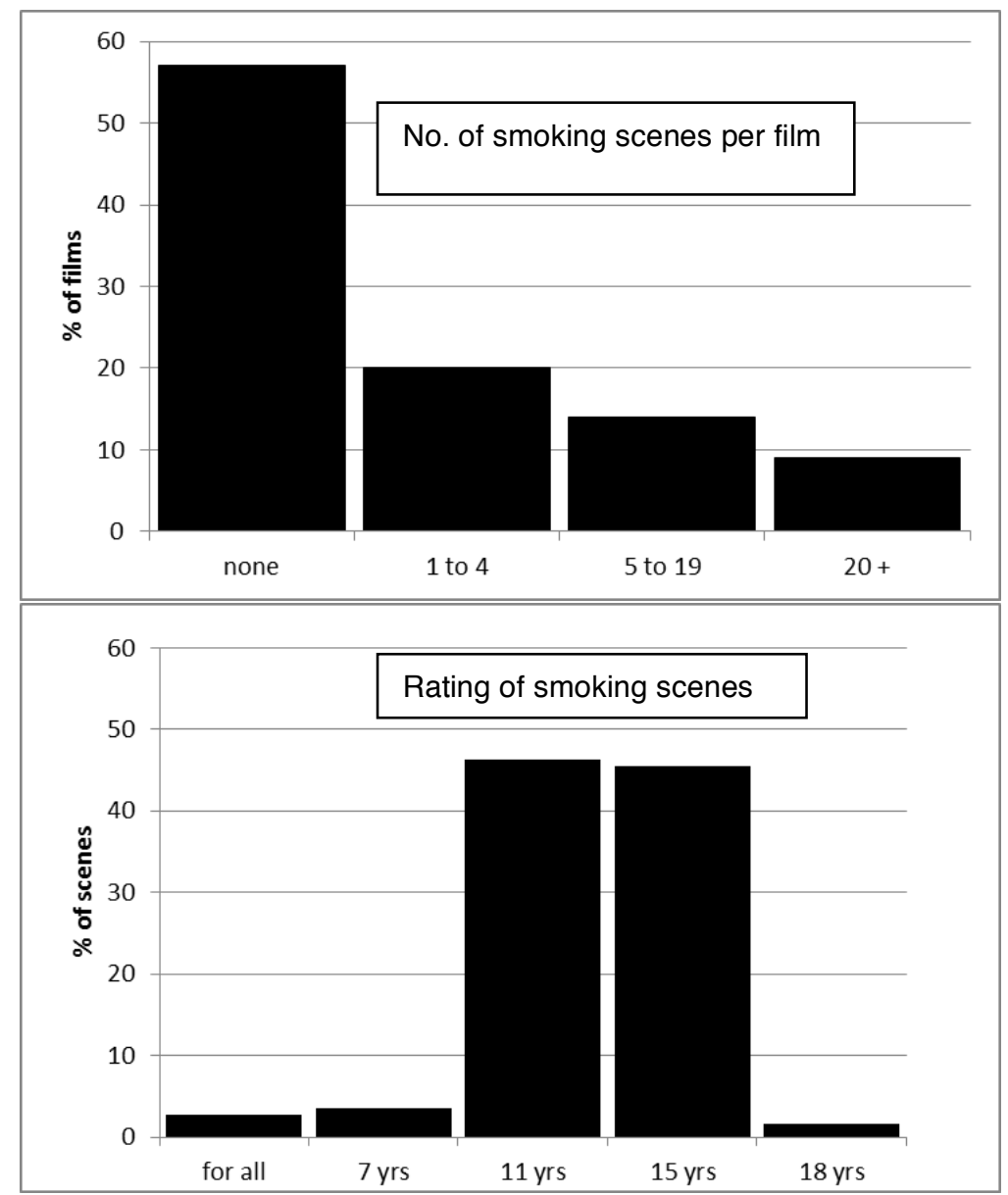

The effect of film-smoking exposure on established smoker status

There was a significant positive unadjusted association between exposure to smoking in films and established smoking (Table 2). Respondents in the fourth quartile, those with the highest exposure to film smoking, were more likely to be established smokers $(\mathrm{OR}=2.52, \mathrm{Cl}=1.42-4.47, \mathrm{p}=.002)$. The association remained significant after adjusting for socio-demographic background covariates and individual traits and social influence from family and peers $(\mathrm{OR}=2.22, \mathrm{Cl}=1.04-4.77, \mathrm{p}=.040)$.

Both demographic and individual factors were significantly associated with smoking status, such that girls, older respondents, and respondents who scored higher on sensation-seeking/rebellion tended more often to be smokers. Notably, respondents who said that half or more of their friends were daily or occasional smokers had about ten times higher odds for being established smokers themselves. 
Table 2: Unadjusted and adjusted relationships between exposure to smoking in films and established smoking, controlling for sociodemographics (2), individual traits (3) and social influence (4) $(\mathrm{N}=805)$. Logistic regression, odds ratios $(95 \% \mathrm{Cl})$.

\begin{tabular}{|c|c|c|c|c|}
\hline $\begin{array}{l}\text { Independent } \\
\text { variables }\end{array}$ & $\begin{array}{l}\text { Model 1: Film- } \\
\text { smoking exposure, } \\
\text { unadjusted }\end{array}$ & $\begin{array}{l}\text { Model } 2: 1+ \\
\text { adjusted for socio- } \\
\text { demographics }\end{array}$ & $\begin{array}{l}\text { Model } 3: 2+\text { adjusted } \\
\text { for individual traits }\end{array}$ & $\begin{array}{l}\text { Model } 4: 3+\text { adjusted } \\
\text { for social influence }\end{array}$ \\
\hline \multicolumn{5}{|l|}{$\begin{array}{l}\text { Film-smoking } \\
\text { exposure }\end{array}$} \\
\hline $1^{\text {st }}$ quartile & 1.00 & 1.00 & 1.00 & 1.00 \\
\hline $2^{\text {nd }}$ quartile & $.99(.51-1.95)$ & $.86(.43-1.72)$ & $.89(.42-1.88)$ & $.78(.32-1.93)$ \\
\hline $3^{\text {rd }}$ quartile & $1.40(.75-2.61)$ & $1.11(.59-2.1)$ & $1.07(.53-2.13)$ & $.95(.42-2.16)$ \\
\hline $4^{\text {th }}$ quartile & $2.52(1.42-4.47)^{\star \star \star}$ & $2.26(1.24-4.14)^{\star \star \star}$ & $2.46(1.47-4.12)^{\star \star}$ & $2.22(1.04-4.77)^{\star \star}$ \\
\hline \multicolumn{5}{|l|}{$\begin{array}{l}\text { Socio- } \\
\text { demographics: }\end{array}$} \\
\hline Gender & & $1.75(1.11-2.76)^{\star \star}$ & $2.46(1.47-4.12)^{\star \star \star \star}$ & $2.14(1.18-3.90)^{\star \star}$ \\
\hline \multicolumn{5}{|c|}{ - } \\
\hline $15-16$ & & 1.00 & 1.00 & 1.00 \\
\hline $17-18$ & & $4.45(2.21-8.94)^{\star \star \star \star}$ & $6.61(3.18-13.74)^{\star * * *}$ & $6.65(2.81-15.73)^{\star \star \star \star}$ \\
\hline $19-20$ & & $7.24(3.65-14.37)^{\star \star \star \star}$ & $17.46(8.12-37.52)^{\star \star \star *}$ & $15.73(6.36-38.91)^{\star * * *}$ \\
\hline \multicolumn{5}{|l|}{ Individual traits: } \\
\hline \multicolumn{5}{|l|}{$\begin{array}{l}\text { Sensation- } \\
\text { seeking/rebellion }\end{array}$} \\
\hline $1^{\text {st }}$ quartile & & & 1.00 & 1.00 \\
\hline $2^{\text {nd }}$ quartile & & & $2.77(1.22-6.31)^{\star \star}$ & $2.24(.88-5.72)^{*}$ \\
\hline $3^{\text {rd }}$ quartile & & & $5.25(2.33-11.83)^{\star \star \star *}$ & $4.56(1.81-11.47)^{\star \star \star *}$ \\
\hline $4^{\text {th }}$ quartile & & & $17.09(7.47-39.09)^{\star \star \star \star}$ & $10.93(4.24-28.17)^{\star \star \star \star}$ \\
\hline \multicolumn{5}{|l|}{ Self-esteem } \\
\hline $1^{\text {st }}$ quartile & & & 1.00 & 1.00 \\
\hline $2^{\text {nd }}$ quartile & & & $.65(.34-1.22)$ & $.70(.33-1.46)$ \\
\hline $3^{\text {rd }}$ quartile & & & $.61(.32-1.16)$ & $.62(.29-1.35)$ \\
\hline $4^{\text {th }}$ quartile & & & $.64(.33-1.23)$ & $.65(.30-1.39)$ \\
\hline \multicolumn{5}{|l|}{ Social influence: } \\
\hline Father smoking & & & & $1.50(.79-2.85)$ \\
\hline Mother smoking & & & & $1.77(.93-3.36)^{\star}$ \\
\hline Siblings smoking & & & & $1.09(.58-2.03)$ \\
\hline Friends smoking & & & & $10.37(5.93-18.13)^{\star \star \star \star}$ \\
\hline Parents drinking & & & & $.64(.37-1.10)$ \\
\hline Friends drinking & & & & $1.65(.88-3.08)$ \\
\hline \multicolumn{5}{|l|}{ Parental style } \\
\hline $1^{\text {st }}$ quartile & & & & 1.00 \\
\hline $2^{\text {nd }}$ quartile & & & & $1.94(.95-3.96)^{\star}$ \\
\hline $3^{\text {rd }}$ quartile & & & & $.87(.39-1.93)$ \\
\hline $4^{\text {th }}$ quartile & & & & $1.51(.67-3.42)$ \\
\hline Nagelkerke & .03 & .14 & .29 & .50 \\
\hline$-2 L L$ & 605,704 & 556,386 & 481,458 & 367,209 \\
\hline Change in -2LL & $* * *$ & $\star * * *$ & $* \star * *$ & $* * * *$ \\
\hline
\end{tabular}

${ }^{*} \mathrm{P}<0.1,{ }^{* *} \mathrm{P}<0,05,{ }^{* * *} \mathrm{P}<0.01,{ }^{* * * *} \mathrm{P}<0.001$ 
Table 3: Unadjusted and adjusted relationships between exposure to smoking in films and susceptibility to smoking among non-smokers, controlling for socio-demographics (2), individual traits (3) and social influence (4) $(\mathrm{N}=630)$. Logistic regression, odds ratios $(95 \% \mathrm{Cl})$.

\begin{tabular}{l} 
Independent \\
variables \\
\\
\hline Film-smoking \\
exposure: \\
$1^{\text {st }}$ quartile \\
$2^{\text {nd }}$ quartile \\
$3^{\text {rd }}$ quartile \\
$4^{\text {th }}$ quartile \\
Socio- \\
demographics: \\
Gender \\
Age \\
$15-16$ \\
$17-18$ \\
$19-20$
\end{tabular}

$\begin{array}{ll}\text { Model 1: Film- } & \text { Model 2: } 1+ \\ \text { smoking exposure, } & \text { adjusted for socio- } \\ \text { unadjusted } & \text { demographics }\end{array}$

Model 3: 2 +

adjusted for

individual traits
Model 4: $3+$ adjusted for social influence

Individual traits:

Sensation-

seeking/rebellion

$$
\begin{aligned}
& 1^{\text {st }} \text { quartile } \\
& 2^{\text {nd }} \text { quartile } \\
& 3^{\text {rd }} \text { quartile } \\
& 4^{\text {th }} \text { quartile }
\end{aligned}
$$

Self-esteem $1^{\text {st }}$ quartile $2^{\text {nd }}$ quartile $3^{\text {rd }}$ quartile $4^{\text {th }}$ quartile

$\begin{array}{llll}1.00 & 1.00 & 1.00 & 1.00 \\ .63(.39-.1 .01)^{\star} & .65(.40-1.06)^{\star} & .69(.42-1.13) & .64(.38-1.08)^{\star} \\ 1.01(.64-1.58) & 1.12(.71-1.77) & 1.08(.67-1.72) & 1.08(.67-1.76) \\ 1.84(1.17-2.89)^{\star \star *} & 1.89(1.18-3.03)^{\star \star \star} & 1.69(1.04-2.74)^{\star *} & 1.55(.93-2.56)^{*}\end{array}$

$\begin{array}{lll}.83(.59-1.18) & .93(.63-1.36) & .90(.60-1.35) \\ 1.00 & 1.00 & 1.00 \\ .54\left(.36-.80^{\star \star \star}\right. & .58(.38-.88)^{\star \star \star} & .51(.33-.78)^{\star \star \star} \\ .73(.49-1.10) & .92(.60-1.42) & .77(.48-1.23)\end{array}$

Social influence:

Father smoking

Mother smoking

Siblings smoking

Friends smoking

Parents drinking

Friends drinking

Parental style

$$
\begin{aligned}
& 1^{\text {st }} \text { quartile } \\
& 2^{\text {nd }} \text { quartile } \\
& 3^{\text {rd }} \text { quartile } \\
& 4^{\text {th }} \text { quartile }
\end{aligned}
$$

$\begin{array}{lc}1.00 & 1.00 \\ .84(.53-1.32) & .82(.51-1.31) \\ 1.62(1.00-2.64)^{\star} & 1.69(1.02-2.83)^{\star \star} \\ 2.55(1.49-4.36)^{\star \star \star \star} & 2.45(1.38-4.35)^{\star \star \star} \\ & \\ 1.00 & 1.00 \\ 1.29(.78-2.13) & 1.27(.76-2.13) \\ 1.05(.64-1.71) & 1.10(.65-1.84) \\ .83(.50-1.39) & .88(.52-1.52)\end{array}$

$63(.38-1.05)^{*}$

$1.74(1.10-2.76)^{\star *}$

$1.31(.82-2.11)$

$1.26(.74-2.16)$

$1.92(1.34-2.76)^{\star \star \star \star}$

1.25 (.85-1.83)

1.00

$1.14(.68-1.89)$

$.84(.52-1.37)$

1.07 (.62-1.84)

$\begin{array}{lllll}\text { Nagelkerke } & .04 & .07 & .12 & .17 \\ -2 \text { LL } & 813.649 & 802,697 & 775,821 & 748,618 \\ \text { Change in -2LL } & * \star * * & * * * * * *\end{array}$

${ }^{\star} \mathrm{P}<0.1,{ }^{* *} \mathrm{P}<0,05,{ }^{\star * *} \mathrm{P}<0.01,{ }^{* \star *} \mathrm{P}<0.001$ 


\section{The effect of film-smoking exposure on susceptibility to smoking}

A significant unadjusted association was found when susceptibility to smoking among non-smokers was regressed on exposure to film smoking (for the fourth quartile: $\mathrm{OR}=1.84, \mathrm{Cl}=1.17-2.89, \mathrm{p}=.009$ ) (Table 3). As was the case with established smoking, the association held up after controlling for sociodemographics, individual variables, and social-influence variables, albeit at a low level of significance in the most elaborate model $(\mathrm{OR}=1.55, \mathrm{Cl}=.93-2.56$, $\mathrm{p}=.090)$.

In addition to exposure to smoking in films, age, sensation-seeking, maternal smoking, and parental drinking patterns were significantly associated with susceptibility to smoking.

\section{Tracing interaction effects}

Three-way analyses of associations between exposure to smoking in films and susceptibility to smoking, controlling for social influence (one factor at a time), suggested that exposure to smoking in films might be of particular relevance for low-risk groups (Figure 2). For five of the six social-influence factors, there were significant positive associations between exposure to smoking in films and susceptibility to smoking in low-risk categories (the exception was less than half of friends drinking'). Similar effects were found for low sensationseeking/rebellion, but not for low self-esteem. This pattern was also found in relation to established smoking, social influence, and film-smoking exposure (figure not shown).

Figure 2: Prevalence of susceptible non-smokers (y-axis) by filmsmoking exposure in quartiles (x-axis), in 'low risk' social influence groups. Three-way analyses.

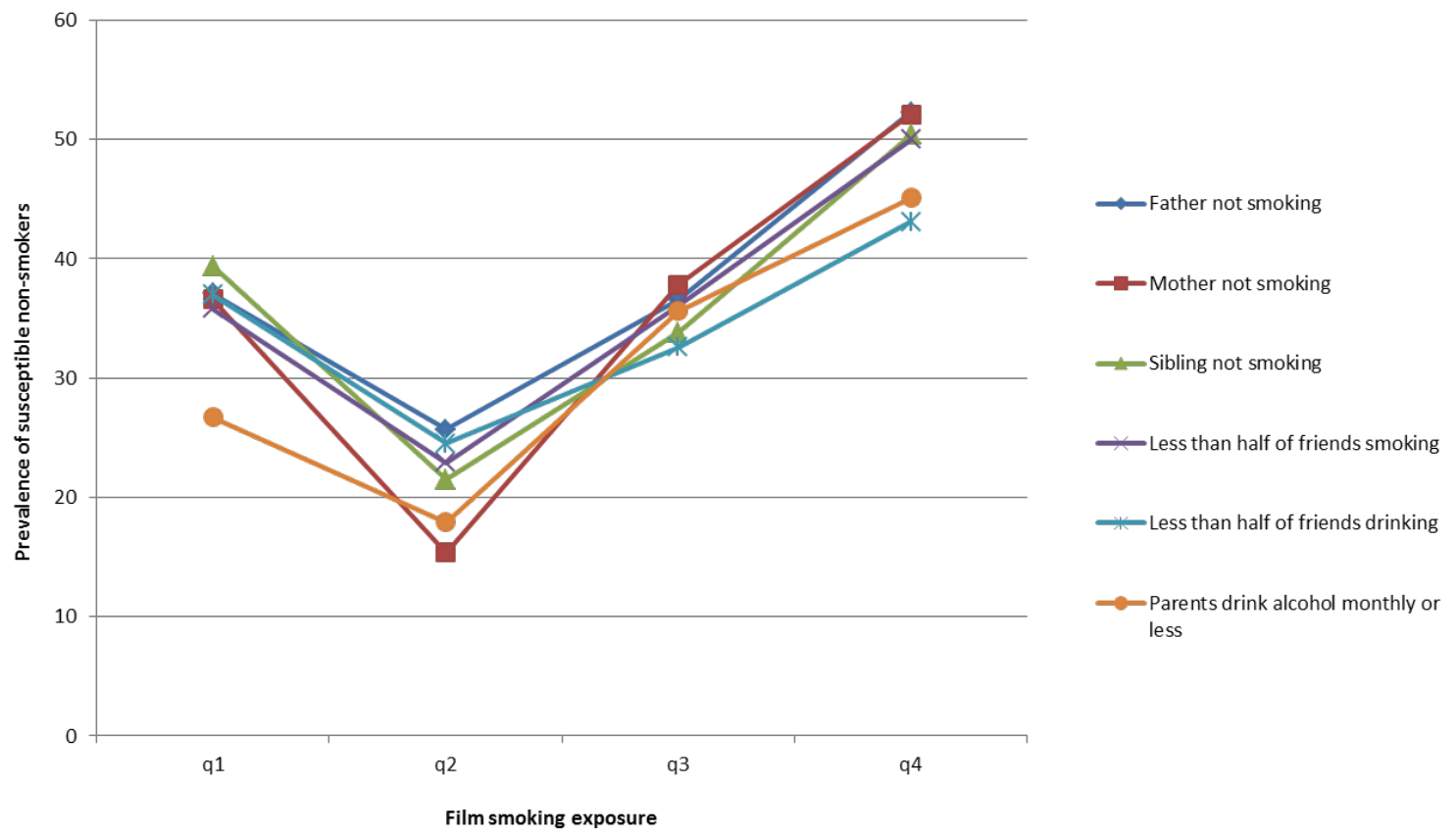




\section{Discussion}

We have presented findings from the first investigation of exposure to smoking in films and smoking susceptibility and initiation among adolescents and young adults based on data from Scandinavia. The study, moreover, is both the first from outside the US to look at older adolescents and the first to explore interaction effects among youth over 15 years of age. The findings show that exposure to smoking in films is associated with smoking behaviour even in the specific and relatively homogenous Scandinavian culture. Thus, this study supports previous major findings reported in the literature.

More precisely, this study suggests that exposure to smoking in films may contribute to the development of susceptibility to smoking among non-smoking youth. It is widely accepted that susceptibility theoretically constitutes the initial step in the process of the influence of the media on adolescent smoking behaviour (Sargent, 2006), and the findings indicate that this step is empirically supported in Norway. Furthermore, the analysis of established smoking, which shows that exposure to smoking in films is also associated with this outcome measure after statistical adjustments for all other major risk factors, suggests that the exposure to smoking in films is most likely an independent risk factor for the initiation of smoking. The results of this study imply that similar processes of the influence of smoking in films are in operation in Norway, as they are in countries like the US, Mexico, the UK, Germany, and the Netherlands.

\section{Limitations}

Before discussing our results in more detail, we would like to acknowledge some of the limitations of this study. First, the cross-sectional and observational design of this study makes it difficult to assess the temporal sequence of events, and so these analyses cannot be used to justify the assumption that exposure to film smoking causes smoking susceptibility or smoking initiation. However, it is worth noting that in the international literature these relationships are often considered to be of a causal nature (US National Cancer Institute, 2008).

Secondly, the response rate of the study was rather low. Even if there were no indications of this factor challenging the representativeness of the data, it did result in a sample size with a limited statistical power to explore interaction terms in the regressions fully. In addition, one effect was significant at a moderate level of significance only $(p<0,1)$. However, as the overall findings are in accordance with those of similar studies from abroad, it is likely that the results are valid despite these limitations.

\section{Age}

Regarding the research problem under scrutiny, we may note that the respondents in this study were relatively old (15-20-year-olds). Social-learning theory suggests that the influence of film smoking on smoking susceptibility and initiation starts at a much earlier stage in life. Empirical studies from the US have uncovered effects of this process among children as young as eight years (Titus-Ernstoff et al., 2008), and usually on children and young adolescents between ten and 14 years (Dalton et al., 2003, Sargent el al., 
2005), indicating that exposure to smoking in films might already have resulted in established smoking for many 15-20-year-olds. Still, as 'older' adolescents and young adults have not been much studied in the film-smoking literature, it is interesting to observe that associations between exposure to smoking in films and smoking behaviour are statistically significant even for adolescents approaching adulthood (Song et al., 2007; Dalton et al., 2009). And, of course, there is nothing in the literature on socialization which suggests that 15-20year-olds are not subjected to the effects of the media, even if an emphasis on this age group may involve a smaller and 'attenuated' effect of exposure to smoking in films (Hunt et al., 2009). It is conceivable, for instance, that the relative importance of exposure to smoking in films (and also parental smoking) is lower towards the end of the teenage years, and may be partly overshadowed by peer smoking (Dal Cin et al., 2012).

\section{Interaction effects}

The findings unambiguously support the argument that a sensation-seeking personality and social factors - particularly peer smoking and parental drinking - are important risk factors for adolescent smoking experimentation and, indeed, initiation too, indicating perhaps that exposure to smoking in films for some adolescents is only one part of a lifestyle charged with risk-seeking behaviour.

Interestingly, a three-way investigation also revealed that exposure to smoking in films had a strong independent effect even within groups who were otherwise at low risk. More precisely, regardless of having parents who do not smoke or drink excessively, or having many non-smoker friends, a high exposure to smoking scenes in films increases the risk of being susceptible to smoking or being an established smoker. These findings, indicating a moderating effect, are also in accordance with similar findings from the US (Dalton et al., 2003) and Germany (Hanewinkel \& Sargent, 2008). This effect (which is probably largely cognitive, and according to this study may continue well into the end of the teenage years) is important to restrain, as it affects young people who should have good prospects not to become smokers. It is in this light that policy-makers, who aim to prevent the initiation of smoking among adolescents, must consider regulation of smoking scenes by raising the age limits.

\section{Linearity}

In contrast to many (though not all) international studies, our findings were not linear 'dose-response' associations. This may be due to some of the following characteristics of the study: the sample of films was smaller than in most other studies, and contained only contemporary films, not recently popular films (for instance including the last five years). Consequently, the total number of smoking scenes that a respondent theoretically could be exposed to was small compared with the situation in studies using, for example, the Dartmond Medical School's design and data set (Sargent et al., 2001; Dalton et al., 2003; Islam \& Johnson, 2007; Hunt et al., 2011, Morgenstern et al., 2011), where 50 titles are randomly selected from a larger sampling pool of 500-600 films. Our approach, with a fixed sample of 56 titles, may have underestimated possible underlying variance that might have been more adequately assessed by using 
a larger number of total smoking scenes. Additionally, repeated viewing was not taken into consideration (Hunt et al., 2011).

Having said that, we may note that the fact that the 'film-smoking-exposure effect' is supported by means of data sets other than Dartmond's might be construed to demonstrate the robustness of this effect, and is consequently an added support for the underlying hypothesis.

However, deviations from stringent dose-response patterns may not necessarily be due to methodological matters. One may also ponder possible substantial explanations, for example, whether the lack of stringent doseresponse patterns may reflect underlying cultural dimensions rather than statistical anomalies. In our Norwegian study we found monotonous curvilinear associations, just like those previously found in Iceland, which is quite similar to Norway in respect of culture and history (Morgenstern et al., 2011, 2013). On the other hand, data from Italy and Poland have displayed nonmonotonous (reversed) curvilinear associations, differing not only from the Nordic countries, but also from the US and Germany (Morgenstern et al., 2011). As far as we know, no one has attempted to test whether such intercountry differences may be due to possible moderating factors like religious affiliation, different smoking cultures in Southern and Eastern Europe (and consequently differences in perceived smoking norms) or even local resistance to Hollywood-style cultural imperialism.

It is perhaps noteworthy that these kinds of effects occur at all in relatively egalitarian countries such as Norway, with smaller differences in relation to economic capital distribution (OECD, 2014; Wilkinson \& Pickett, 2010) and lower smoking prevalence than most other countries (WHO, 2015). A largely shared common culture in the Scandinavian region involves widespread sharing of local practices and understanding, which could potentially act as a kind of cultural resistance towards assimilation. As most of the films in this study are American - and thus different from Norwegian movies in language and maybe even values - we could expect that Norwegian adolescents would identify less with smoking characters in American movies than American adolescents, and, consequently, be less influenced. What we found however was a tendency of all movies to influence Norwegian adolescents and young adults. Presumably, the influence of American films works largely via assimilating youth (in Norway, like the rest of the west) into the stories and their associated values. Accordingly, there are no indications of an overall cultural resistance towards Hollywood culture (as is found among blacks in the US).

\section{Future research}

Future research on this issue in Norway should not only consider a prospective or longitudinal design (to meet with the demands of causality), but also a better measure of exposure. Future research in this field could investigate the role of cultural dimensions (like religion, smoking culture, local resistance to cultural imperialism) that have yet to be accounted for as possible moderators (or mediators) in the largely socio-psychological model that has dominated previous research. Finally, it will also be of interest to look into relationships between adolescents' cultural backgrounds (including ethnicity, which has not been an issue in this study), film-genre preferences, 
and identification with various characters on the screen, for example, in relation to exposure to domestic versus foreign films.

\section{Conclusion}

The findings in this study suggest that exposure to smoking in films is an independent risk factor for developing smoking susceptibility among nonsmokers. With regard to established smoking, the findings suggest that exposure to smoking in films contributes to smoking behaviour in Norway, along with gender, age, sensation-seeking, and peer influence. From a publichealth perspective, this illustrates why films with smoking scenes might deserve an '18-years' rating in the future.

\section{Acknowledgements}

This work was supported by Norwegian Institute for Alcohol and Drug Research (SIRUS).

\section{References}

Dal Cin, S., Stoolmiller, M. \& Sargent, J.D. (2012). When movies matter: Exposure to smoking in movies and changes in smoking behavior. Journal of Health Communication, 17(1), 76-89.

Dal Cin, S., Stoolmiller, M. \& Sargent, J.D. (2013). Exposure to smoking in movies and smoking initiation among black youth. American Journal of Preventive Medicine, 44(4), 345-350.

Dalton, M., Beach, M., Adachi-Mejia, A. et al. (2009). Early exposure to movie smoking predicts established smoking by older teens and young adults. Pediatrics, 123(4), e551-558.

Dalton, M.A., Sargent, J.D., Beach, M.L., et al. (2003). Effect of viewing smoking in movies on adolescent smoking initiation: A cohort study. Lancet, 362(9380), 281-285.

Dalton, M.A., Tickle, J.J., Sargent, J.D., et al. (2002). The incidence and context of tobacco use in popular movies from 1988 to 1997. Preventive Medicine, 34(5), 516-523.

Hanewinkel, R. \& Sargent, J.D. (2008). Exposure to smoking in internationally distributed American movies and youth smoking in Germany: A cross-cultural cohort study. Pediatrics, 121(1), e108-117.

Hanewinkel, R. \& Sargent, J.D. (2007). Exposure to smoking in popular contemporary movies and youth smoking in Germany. American Journal of Preventive Medicine, 32(6), 466-473. 
Hanewinkel, R., Sargent, J.D., Karlsdóttir, S., et al. (2013). High youth access to movies that contain smoking in Europe compared with the USA. Tobacco Control, 22(4), 241-244.

Hines, D., Saris, R.N. \& Throckmorton-Belzer, L. (2000). Cigarette smoking in popular films: Does it increase viewers' likelihood to smoke? Journal of Applied Social Psychology, 30(11), 2246-2269.

Hunt, K., Henderson, M., Wight, D., et al. (2011). Exposure to smoking in films and own smoking among Scottish adolescents: a cross-sectional study. Thorax, 66(10), 866-874.

Hunt, K., Sweeting, H., Sargent, J.D., et al. (2009). An examination of the association between seeing smoking in films and tobacco use in young adults in the west of Scotland: cross-sectional study. Health Education Research, 24(1), 22-31.

Islam, S.M.S. \& Johnson, C.A. (2007). Western media's influence on Egyptian adolescents' smoking behavior: The mediating role of positive beliefs about smoking. Nicotine \& Tobacco Research, 9(1), 57-64.

Jackson, C., Brown, J.D. \& L'Engle, K.L. (2007). R-Rated movies, bedroom televisions, and initiation of smoking by white and black adolescents. Archives of Pediatrics and Adolescent Medicine, 161(3), 260-268.

Jackson, C., Henriksen, L. \& Foshee, V.A. (1998). The authoritative parenting index: predicting health risk behaviors among children and adolescents. Health Education and Behavior, 25(3), 319-337.

Lochbuehler, K., Peters, M., Scholte, R.H., et al. (2010). Effects of smoking cues in movies on immediate smoking behaviour. Nicotine \& Tobacco Research, 12(9), 913-918.

Lochbuehler, K., Voogd, H., Scholte, R.H., et al. (2011). Attentional bias in smokers: exposure to dynamic smoking cues in contemporary movies. Journal of Psychopharmacology, 25(4), 514-519.

McMillen, R.C., Tanski, S., Winickoff, J.P., et al. (2007). Attitudes about smoking in the movies. Social Climate Survey of Tobacco Control. Mississippi State University Social Science Research Center, American Academy of Pediatrics.

Millett, C. \& Glantz, S.A. (2010). Assigning an '18' rating to movies with tobacco imagery is essential to reduce youth smoking (editorial). Thorax, 65(5), 377-337.

Morgenstern, M., Poelen, E.A.P., Scholte, R., et al. (2011). Smoking in movies and adolescent smoking: cross-cultural study in six European countries. Thorax, 66(10), 875-882.

Morgenstern, M., Sargent, J.D., Engels, R.C, et al. (2013). Smoking in movies and adolescent smoking initiation: longitudinal study in six European countries. American Journal of Preventive Medicine, 44(4), 339-344.

OECD Income distribution statistics http://stats.oecd.org/Index.aspx?DatasetCode=IDD

Pechmann, C. \& Shih, C. (1999). Smoking in movies and antismoking advertisements before movies: Effects on youth. Journal of Marketing, 63(3), 1-13.

Pierce, J.P., Choi, W.S., Gilpin, E.A., et al. (1996). Validation of susceptibility as a predictor of which adolescents take up smoking in the United States. Health Psychology, 15(5), 335-361. 
Primack, B.A., Longacre, M., Beach, M.L., et al. (2012). Established smoking among adolescents and its association with early and late exposure to smoking depicted in movies. Journal of Adolescent Health, 50(2), S13.

Sargent, J. (2006). Smoking in film and impact on adolescent smoking: with special reference to European adolescents. Minerva Pediatrica, 58(1), 27-45.

Sargent, J.D., Beach, M.L., Adachi-Mejia, A., et al. (2005). Exposure to movie smoking: its relation to smoking initiation among US adolescents. Pediatrics, 116(5), 1183-1191.

Sargent, J.D., Beach, M.L., Dalton, M.A., et al. (2001). Effect of seeing tobacco use in films on trying smoking among adolescents: cross sectional study. BMJ, 323(7326), 1394-1397.

Sargent, J.D., Dalton, M.A., Beach, M.L., et al. (2002). Viewing tobacco use in movies: Does it shape attitudes that mediate adolescent smoking? American Journal of Preventive Medicine, 22(3), 137-145.

Sargent, J.D., Stoolmiller, M., Worth, K.A., et al. (2007). Exposure to smoking depictions in movies: Its association with established adolescent smoking. Archives of Pediatrics and Adolescent Medicine, 161(9), 849-856.

Skretting, A., Bye, E.K., Vedøy, T.F., et al. (2015) Rusmidler i Norge 2014. Oslo: SIRUS. http://www.sirus.no/wp-content/uploads/2015/03/RIN2014norsk.pdf.

Song, A.V., Ling, P.M., Neilands, T.B., et al. (2007). Smoking in movies and increased smoking among young adults. American Journal of Preventive Medicine, 33(5), 396-403.

Thrasher, J.F., Jackson, C., Arillo-Santillan, E., et al. (2008). Exposure to smoking imagery in popular films and adolescent smoking in Mexico. American Journal of Preventive Medicine, 35(2), 95-102.

Thrasher, J.F., Sargent, J.D., Huang, L., et al. (2009). Does film smoking promote youth smoking in middle-income countries? A longitudinal study among Mexican adolescents. Cancer Epidemiology, Biomarkers \& Prevention, 18(12), 34443450 .

Titus-Ernstoff, L., Dalton, M.A., Adachi-Mejia, A.M., et al. (2008). Longitudinal study of viewing smoking in movies and initiation of smoking by children. Pediatrics, 121(1), 15-21.

US National Cancer Institute (2008). Monograph 19: The role of the media in promoting and reducing tobacco use. Bethesda, MD: US National Institutes of Health.

Vedøy, T.F. \& Skretting, A. (2009). Young people and drugs. Results from questionnaires 1968-2008 (in Norwegian). Oslo: Norwegian Institute for Alcohol and Drug Research; SIRUS-rapport 5/2009.

Waylen, A.E., Leary, S.D., Ness, A.R., et al. (2011). Cross-sectional association between smoking depictions in films and adolescent tobacco use nested in a British cohort study. Thorax, 66(10), 856-861.

Wilkinson, A.V., Spitz, M.R., Prokhorov, A.V., et al. (2009). Exposure to smoking imagery in the movies and experimenting with cigarettes among Mexican heritage youth. Cancer Epidemiology, Biomarkers \& Prevention, 18(12), 34353443.

Wilkinson, R. \& Pickett, K. (2010). The spirit level. Why equality is better for everyone. London: Penguin Books. 
World Health Organization (2011). Smoke-free movies: From evidence to action (2nd ed.). Geneva, Switzerland: World Health Organization.

World Health Organization (2015). WHO global report on trends in prevalence of tobacco smoking 2015. Geneva, Switzerland: World Health Organization. http://www.who.int/tobacco/publications/surveillance/reportontrendstobaccosmo king/en/ 